\title{
Presentation of preliminary results of an experiment on the sorption of metals on the surface of microplastic particles in the natural waters of Karelia
}

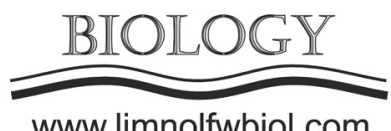

www.limnolfwbiol.com

\author{
Kulik N.V. ${ }^{1 *}$, Efremenko N.A. ${ }^{1}$, Kovalesky V.V. ${ }^{2}$, Rozhkova V.S. ${ }^{2}$ \\ ${ }^{1}$ Northern Water Problems Institute of the Karelian Research Centre of the RAS, Aleksander Nevsky st., 50, Petrozavodsk, 185030, \\ Russia \\ ${ }^{2}$ Institute of Geology of the Karelian Research Centre of the RAS, Pushkinskaya St., 11, Petrozavodsk, 185910, Russia
}

\begin{abstract}
The paper presents preliminary results of a model experiment on the sorption of metals on the surface of microplastic particles (MP) in the conditions of natural waters of Karelia. It was found that the interaction of the studied metals with MP particles is different and largely depends on the concentration of elements and the content of organic matter in the studied aqueous samples, the size of the microplastic particles. The results showed that the sorption of metals on the surface of the particles increases with time, while iron will be one of the first to be sorbed, since its content is an order or two higher than all other metals.
\end{abstract}

Keywords: microplastic particles, sorption, metals, natural waters

\section{Introduction}

Pollution of the environment with microplastic (MP) is an urgent problem in recent decades. One of the areas of research is control over the interaction of natural water metals with microplastic particles. The sorption of metals by microplastic particles depends on a large number of factors, including both the properties of metals, the properties of the medium in which sorption occurs, and the state of the microplastic particles themselves. Depending on this, the interaction of metals with polymers can vary significantly (Kazmiruk, 2020). To study the sorption of metals in fresh waters with different colors, a model experiment was conducted and the sorption of metals in the water of Lake Onega and in the water of one of its tributaries, the Shuya River, was evaluated.

\section{Material and methods}

A plastic sample (macroplastic) - an aged PET bottle (brown), was selected in 2016 during preliminary studies on the northern shore of Lake Ladoga. Plastic was crushed mechanically using a grater and a highspeed mill, a large fraction was selected. Electron microscopic study of microplastics was carried out using a VEGA II LSH scanning electron microscope (Tescan) with an INCA Energy 350 energy dispersive microanalyzer (Oxford instruments).

Water samples were taken in September 2019 in the waters of Lake Onega: Petrozavodsk Bay (station P1); Central Onego (station C3) and a sample of water from the Shuya river. Water sampling for chemical analysis was carried out with a Ruttner fluoropolymer bathometer in 5 liter canisters of high density polyethylene, in the laboratory the samples were filtered through a $0.45 \mu \mathrm{m}$ membrane filter and stored in a refrigerator at $4{ }^{\circ} \mathrm{C}$ until the experiment. In the initial water samples, the $\mathrm{pH}$, color and metal concentrations were determined by inductively coupled plasma mass spectrometry (ICP-MS) and atomic absorption methods: $\mathrm{Fe}, \mathrm{Mn}$ - with atomization of samples in a flame, $\mathrm{Zn}, \mathrm{Cu}$, $\mathrm{Pb}, \mathrm{Cd}, \mathrm{Ni}$ - with electrothermal atomization of samples (optional).

To determine the concentration of metals sorbed on the surface of MP particles, an extraction technique was set up with a further determination of the concentration of: iron - atomic absorption method; $\mathrm{Mn}, \mathrm{Cu}, \mathrm{Ni}, \mathrm{Zn}, \mathrm{Cr}, \mathrm{Pb}, \mathrm{Cd}$ - by inductively coupled plasma mass spectrometry. The proposed methods allow to obtain reliable results for different types of water, differing in such parameters as color, $\mathrm{pH}$, initial concentrations of metals in water.

\section{Results and discussion}

Electron microscopic examination of microplastic showed that the sample has a plate-like cleaved surface with many microparticles of the plastic itself, and inclusions of $\mathrm{Fe}, \mathrm{Cu}$, and other metals. 
The observed concentrations of $\mathrm{Cu}, \mathrm{Ni}, \mathrm{Cr}, \mathrm{Cd}$, $\mathrm{Pb}$, and $\mathrm{Zn}$ in the initial water samples were two to three orders of magnitude lower than the concentration of $\mathrm{Fe}$, in some samples an order of magnitude lower than the concentration of Mn, so it was likely to assume that iron and manganese.

As experience has shown, in the initial water samples of the Petrozavodsk Bay there is a decrease in iron concentration in the first day. After a week, its concentration is almost halved. The iron content in the initial samples that were not in contact with plastic, according to the analysis results, after a month of the experiment remained practically unchanged (P1-119; Shuya - 253; "C3" - $67 \mu \mathrm{g} / 1$ ). Along with iron, a decrease in the concentration of manganese and zinc is noted; after 72 hours of interaction, a two-fold decrease in the content of elements was recorded. A halving of the content is also observed for chromium, but after 168 hours. Almost at the level of initial concentrations, the content of copper, nickel and cadmium remains.

For the initial water sample p. The shuya picture is almost the same as for the water sample of the Petrozavodsk Bay, except that the iron content decreases more smoothly, and after 168 hours its concentration decreases by no more than $30 \%$. It is likely that the content of organic matter plays an important role in this process. So, for samples with a high color value, which is an indirect indicator of the content of organic matter, the iron concentration in the samples of the Shuya river (124 degrees of color) after 168 hours decreased by $30 \%$, while for samples "C3" (color 33 degrees. ) and samples P1 (color 52 degrees.) a decrease in concentration was observed in half.

The results are consistent with the findings of previous studies (Rochman et al., 2014). It should be noted that a similar picture of a decrease in metal concentrations is observed under natural conditions on naturally suspended particles (Rochman et al., 2014), as well as in unfiltered samples if the samples are stored without preservation (Analiticheskiye, kineticheskiye i raschetnyye metody..., 2017).

\section{Conclusions}

When setting up the experiment, it was found that the interaction of the studied metals with MP particles is different and largely depends on the concentration of elements and the content of organic matter in the studied aqueous samples, the size of the microplastic particles. The results showed that the sorption of metals on the surface of MP particles increases with time, while iron will be one of the first to be sorbed, since its content is an order or two higher than all other metals.

\section{Acknowledgments}

The study was supported by RSF research project \#19-17-00035.

\section{References}

Analiticheskiye, kineticheskiye i raschetnyye metody $\mathrm{v}$ gidrokhimicheskoy praktike [Analytical, kinetic and calculation methods in hydrochemical practice]. 2017. In: Lozovik P.A., Efremenko N.A. (Eds.). St. Petersburg: NestorIstoriya. (in Russian)

Kazmiruk V.D. 2020. Microplastic in the environment: a growing problem on a planetary scale. Moscow: URSS. (in Russian)

Rochman Ch.M., Hentschel B.T., Teh S.J. 2014. Long-term sorption of metals is similar among plastic types: implications for plastic debris in aquatic environments. PLoS ONE. 9. DOI: 10.1371/journal.pone.0085433 